\title{
Periodic Pulses of Calcium Ions in a Chemical System
}

\author{
Krisztina Kurin-Csörgei, ${ }^{\dagger}$ Irving R. Epstein,*,* and Miklós Orbán*,† \\ Department of Inorganic and Analytical Chemistry, L. Eötvös University, H-1518 Budapest 112, \\ P.O. Box 32, Hungary, and Department of Chemistry and Volen Center for Complex Systems, \\ MS 015, Brandeis University, Waltham, Massachusetts 02454-9110
}

Received: April 25, 2006

\begin{abstract}
By coupling the bromate-sulfite-ferrocyanide oscillating chemical reaction with the complexation of calcium ion by EDTA, we construct a system that generates periodic pulses of free $\mathrm{Ca}^{2+}$ with an amplitude of 2 orders of magnitude and a period of ca. $20 \mathrm{~min}$. These pulses may be observed either with a calcium ionselective electrode or with Arsenazo(III) as an indicator. We describe the systematic design procedure and the properties of this first abiotic calcium-based chemical oscillator.
\end{abstract}

\section{Introduction}

The concentrations of many elements undergo periodic oscillations in living organisms. Among abiotic chemical systems, either accidentally discovered or deliberately designed, ${ }^{1}$ oscillatory behavior has largely been limited to a relatively small number of elements that possess several stable oxidation states: the halogens, sulfur, and a few transition metals. ${ }^{2} \mathrm{Re}-$ cently, we developed a systematic design method ${ }^{3}$ that makes it possible to incorporate ions of elements with a single stable nonzero oxidation state into oscillatory chemical processes. Our approach is based on coupling a rapid equilibrium (acid-base, complex formation, or precipitation) involving the target element to a known redox-based core or primary oscillator. To a first approximation, if the oscillator is capable of shifting the equilibrium in both directions during the course of its oscillatory cycle, then all species that participate in the equilibrium are driven to oscillate at the frequency of the core oscillator. In many cases, the most convenient choices for the core system and the corresponding equilibrium reaction are a $\mathrm{pH}$ oscillator and a $\mathrm{pH}$-dependent equilibrium, respectively.

In choosing an appropriate $\mathrm{pH}$ oscillator and the equilibrium reaction to which it is to be coupled in order to generate oscillations in the concentration of a desired species, the following points must be taken into account:

(a) The primary $\mathrm{pH}$ oscillator should function over a wide range of $\mathrm{pH}$ values. To propel the equilibrium between the reactant- and the product-dominated states, the change in $\left[\mathrm{H}^{+}\right]$ during the oscillatory cycle must be sufficiently large.

(b) In addition to being $\mathrm{pH}$-sensitive, the equilibrium reaction must have a moderate equilibrium constant, $K$. If $K$ is too large or too small, the variation in the $\mathrm{pH}$ will be incapable of shifting the equilibrium back and forth. The system instead will remain in either the "reacted" or the "unreacted" state.

(c) If the components of the equilibrium reaction interact with those of the oscillator to any significant extent, the $\mathrm{pH}$ oscillations in the core system may be damped or even eliminated. Anions involved in the equilibrium bind $\mathrm{H}^{+}$in proportion to their Lewis basicities. The higher their concentrations and

*Corresponding authors. E-mail: epstein@brandeis.edu; orbanm@ ludens.elte.hu.

$\dagger$ L. Eötvös University.

$\doteqdot$ Brandeis University. protonation constants, the stronger the buffering effect that they produce. Cations can also destroy the oscillator if they react (e.g., precipitate) with any of the components of the core reaction.

(d) The change in concentration of the target species in the system must be detectable either visually by the formation and destruction of colored species during the oscillatory cycle or with an appropriate sensor, such as an ion-specific electrode (ISE).

In preliminary experiments, we succeeded in inducing oscillations in the concentrations of $\mathrm{Ca}^{2+}, \mathrm{Al}^{3+}$, and $\mathrm{F}^{-}$ions by coupling $\mathrm{pH}$-dependent equilibria involving these species to a $\mathrm{pH}$ oscillator. Calcium oscillations are ubiquitous in biological systems ${ }^{4}$ and therefore building an easily controlled inorganic calcium oscillator is potentially the most significant application of our technique for constructing new oscillators. We present here a detailed study of a new, abiotic calcium ion oscillator.

\section{Experimental Section}

Selection of the Subsystems. Our core system consists of the $\mathrm{BrO}_{3}{ }^{-}-\mathrm{SO}_{3}{ }^{2-}-\mathrm{Fe}(\mathrm{CN})_{6}{ }^{4-}$ (abbreviated as $\mathrm{BSF}$ ) $\mathrm{pH}$ oscillator. ${ }^{5}$ Under appropriate conditions in a flow reactor (CSTR), this reaction exhibits oscillations in $\mathrm{pH},\left[\mathrm{Br}^{-}\right]$, and redox potential with excellent reproducibility. The measured oscillations in $\mathrm{pH}$ lie in the acidic $\mathrm{pH}$ range and have a period of 20-30 min. The range of reactant concentrations yielding oscillatory behavior is relatively narrow at room temperature, but significantly wider at higher temperatures. We therefore conducted all of our experiments at $30{ }^{\circ} \mathrm{C}$. From the phase diagrams presented in ref 5 , the following input concentrations were chosen as our standard composition (given as concentration in the CSTR after mixing but before any reaction takes place): $\left[\mathrm{BrO}_{3}{ }^{-}\right]=6.0 \times 10^{-2} \mathrm{M},\left[\mathrm{SO}_{3}{ }^{2-}\right]=7.5 \times 10^{-2} \mathrm{M},\left[\mathrm{Fe}(\mathrm{CN})_{6}{ }^{4-}\right]$ $=2.0 \times 10^{-2} \mathrm{M}$, and $\left[\mathrm{H}_{2} \mathrm{SO}_{4}\right]=1.0 \times 10^{-2} \mathrm{M}$. At a flow rate of $k_{0}=1.45 \times 10^{-3} \mathrm{~s}^{-1}$ (residence time, $11.5 \mathrm{~min}$ ), the measured characteristics of the oscillations were $\mathrm{pH}_{\min }=2.89$, $\mathrm{pH}_{\max }=6.45$, and period $=28$ min.

For the calcium-containing equilibrium reaction to be coupled to the BSF system, we chose the complex formation between $\mathrm{Ca}^{2+}$ and ethylenediaminetetraacetic acid, disodium salt (EDTA):

$$
\mathrm{Ca}^{2+}+\mathrm{EDTA}^{4-} \leftrightarrow \mathrm{CaEDTA}^{2-}
$$


The formation constant of the complex is $5.01 \times 10^{10}$. The conditional equilibrium constants calculated at $\mathrm{pH} 6.0$ and 3.0 (roughly the $\mathrm{pH}_{\max }$ and $\mathrm{pH}_{\min }$ of the $\mathrm{BSF} \mathrm{pH}$ oscillator) are $K$ $=1.13 \times 10^{6}$ and 1.25 , respectively. ${ }^{6}$ These data suggest that formation of the CaEDTA complex is almost complete at $\mathrm{pH}$ 6.5 , but essentially all the $\mathrm{Ca}^{2+}$ is free at $\mathrm{pH} 3$.

Thus, the BSF $\mathrm{pH}$ oscillator and the formation of the CaEDTA complex, equation 1, constitute a pair of subsystems that fulfill all the selection criteria outlined above.

\section{Materials and Methods}

Stock solutions were prepared by dissolving high-quality Aldrich products $-\mathrm{NaBrO}_{3}, \mathrm{Na}_{2} \mathrm{SO}_{3}, \mathrm{~K} 4 \mathrm{Fe}(\mathrm{CN})_{6}, \mathrm{Na}_{2} \mathrm{H}_{2}$ EDTA $2 \mathrm{H}_{2} \mathrm{O}$ (ethylenediaminetetraacetic acid disodium dihydrate, abbreviated as EDTA), and $\mathrm{CaNa}_{2}$ EDTA (ethylenediaminetetraacetic acid, calcium disodium, abbreviated as CaEDTA)-in deionized water. To ensure good reproducibility in the experiments where $\mathrm{K}_{4} \mathrm{Fe}(\mathrm{CN})_{6}$ and $\mathrm{Na}_{2} \mathrm{SO}_{3}$ were used, special care was taken in the use and storage of these solutions. Stock solutions of $\mathrm{K}_{4} \mathrm{Fe}(\mathrm{CN})_{6}$ were allowed to stand for at least a day before use and were stored in an amber glass container, in which they were stable for several weeks. Solutions of $\mathrm{Na}_{2} \mathrm{SO}_{3}$ were found to react reproducibly if they were used no sooner than an hour after preparation and discarded after 3-4 h.

A thermally regulated CSTR was used for the flow experiments. The reactor had a volume of $45.0 \mathrm{~cm}^{3}$ and operated at $30{ }^{\circ} \mathrm{C}$. No air gap was allowed to form between the surface of the reaction mixture and the Teflon reactor cap. The flow rates employed spanned the range from $k_{0}=2.6 \times 10^{-4}$ to $5.3 \times$ $10^{-3} \mathrm{~s}^{-1}$. The reagents were introduced into the reactor through four inlet tubes via a Gilson Minipuls 2 peristaltic pump. The concentration of the input solutions was thus 4-fold higher than the reported initial concentrations of the reagents in the reactor. Excess reaction mixture was removed either by overflow or by using a second pump. Three signals were monitored during the experiments. The potentiometric progress of the overall reaction was followed with a $\mathrm{Pt}-\mathrm{Hg} / \mathrm{Hg}_{2} \mathrm{SO}_{4} / \mathrm{K}_{2} \mathrm{SO}_{4}$ electrode pair. In addition to the redox potential, either the $\mathrm{pH}$ or $\left[\mathrm{Ca}^{2+}\right]$ was simultaneously measured with a combined glass electrode or a $\mathrm{Ca}^{2+}$ ISE (Orion 93-20) connected to a double channel recorder through a $\mathrm{pH}$ meter. The reaction mixture was stirred, typically at $400 \mathrm{rpm}$, with a magnetic stirrer using a 2-cm-long, 6-mmdiameter Teflon-coated stirring bar.

To construct the calcium oscillator, the BSF pH oscillator and the components of the $\mathrm{Ca}^{2+}+$ EDTA $^{4-} \leftrightarrow \mathrm{CaEDTA}^{2-}$ equilibrium were combined in a well-stirred CSTR. We first initiated the $\mathrm{pH}$ oscillator by introducing the solutions of $\mathrm{NaBrO}_{3}, \mathrm{Na}_{2} \mathrm{SO}_{3}, \mathrm{~K}_{4} \mathrm{Fe}(\mathrm{CN})_{6}$, and $\mathrm{H}_{2} \mathrm{SO}_{4}$ into the reactor. Then the input $\mathrm{NaBrO}_{3}$ solution was replaced with a solution that contained the same concentration of $\mathrm{NaBrO}_{3}$ mixed with CaEDTA.

\section{Results}

To find the optimum input concentrations for generating $\left[\mathrm{Ca}^{2+}\right]$ oscillations in the combined system and to eliminate possible interferences with the response of the $\mathrm{Ca}$-ISE, we had to establish (a) the buffer effect of EDTA on the pH oscillations, (b) the effect of $\mathrm{Ca}^{2+}$ on the BSF oscillator, and (c) the influence of the $\mathrm{pH}$ and the components of the BSF oscillator on the response of the $\mathrm{Ca}-$ ISE.

Buffer Effect of EDTA on the pH Oscillations. Since partially or completely unprotonated EDTA species can bind protons, these species are capable of damping, or even totally suppressing, the $\mathrm{pH}$ oscillations in the core system. If the

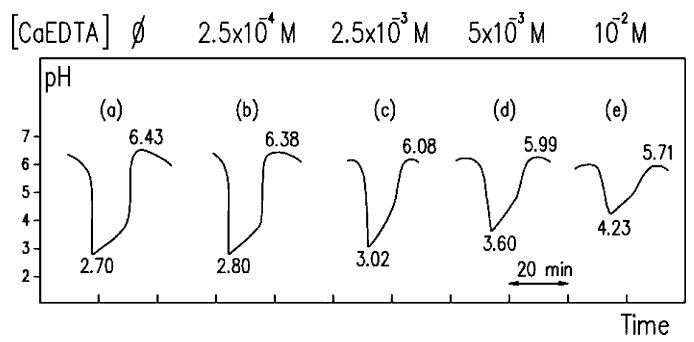

Figure 1. Buffering effect of $\mathrm{EDTA}^{4-}$ on $\mathrm{pH}$ oscillations in the BSF system (one oscillatory cycle is shown for each CaEDTA concentration). Input concentrations: $\left[\mathrm{NaBrO}_{3}\right]=6.5 \times 10^{-2} \mathrm{M},\left[\mathrm{Na}_{2} \mathrm{SO}_{3}\right]=7.5$ $\times 10^{-2} \mathrm{M},\left[\mathrm{K}_{4} \mathrm{Fe}(\mathrm{CN})_{6}\right]=2.0 \times 10^{-2} \mathrm{M},\left[\mathrm{H}_{2} \mathrm{SO}_{4}\right]=1.0 \times 10^{-2}$ $\mathrm{M}$, flow rate: $k_{0}=1.45 \times 10^{-3} \mathrm{~s}^{-1}, T=30^{\circ} \mathrm{C},[$ CaEDTA] $=0 \mathrm{M}$ (a), $2.5 \times 10^{-4} \mathrm{M}(\mathrm{b}), 2.5 \times 10^{-3} \mathrm{M}(\mathrm{c}), 5.0 \times 10^{-3} \mathrm{M}(\mathrm{d})$, and $1.0 \times$ $10^{-2} \mathrm{M}(\mathrm{e})$

concentration of these species becomes too high as a result of the dissociation of CaEDTA at low $\mathrm{pH}$, the $\mathrm{pH}$-driven $\mathrm{BSF}$ oscillator may cease to function. To determine the optimum amount of CaEDTA to mix with the BSF system, we measured the oscillatory $\mathrm{pH}$ range as a function of added [CaEDTA]. Figure 1 depicts the buffering effect of EDTA released from CaEDTA at low $\mathrm{pH}$ values. When [CaEDTA] in the CSTR increases, the amplitudes of both the $\mathrm{pH}$ and the redox potential oscillations decrease, and above a critical level of added CaEDTA $\left(>10^{-2} \mathrm{M}\right)$ no oscillations appear. The "standard composition" BSF $\mathrm{pH}$ oscillator maintains an amplitude for $\left[\mathrm{EDTA}^{4-}\right.$ ] levels as high as $5 \times 10^{-3} \mathrm{M}$. Somewhat smaller buffer effects are observed when the EDTA is introduced in the form of $\mathrm{Na}_{2} \mathrm{H}_{2}$ EDTA. From these experiments, we conclude that combining the standard BSF oscillator with $2.5 \times 10^{-3} \mathrm{M}$ CaEDTA yields a system producing high-amplitude $\mathrm{Ca}^{2+}$ pulses in the CSTR.

Response of the $\mathrm{Ca}-\mathrm{ISE}$ to $\left[\mathrm{Ca}^{2+}\right],\left[\mathrm{H}^{+}\right]$, and the Components of the BSF Oscillator. The $\mathrm{Ca}-\mathrm{ISE}$ used in our experiments showed a linear Nernstian response to $\left[\mathrm{Ca}^{2+}\right]$ with a slope of $27 \mathrm{mV} /$ decade in the concentration range $10^{-5} \mathrm{M} \leq$ $\left[\mathrm{Ca}^{2+}\right] \leq 10^{-1} \mathrm{M}$.

The response of the $\mathrm{Ca}-\mathrm{ISE}$ may also depend on the concentrations of $\mathrm{H}^{+}$and the components of the BSF oscillator. We therefore performed a series of measurements to assess the operation of the $\mathrm{Ca}$-ISE in the oscillatory mixture. The responses of $\mathrm{Ca}-\mathrm{ISE}$ and glass and $\mathrm{Pt}$ electrodes were recorded in the presence of $1.0 \times 10^{-3}$ to $2.5 \times 10^{-3} \mathrm{M} \mathrm{Ca}^{2+}\left(\right.$ as $\left.\mathrm{CaCl}_{2}\right)$ in the BSF oscillatory mixture. The $\mathrm{Ca}-\mathrm{ISE}$ gives a nearly constant signal, whereas the glass and Pt electrodes respond in an oscillatory manner without noticeable changes in the amplitude and frequency from the values found in the $\mathrm{Ca}^{2+}$ free system. These results demonstrate that (i) changes in $\mathrm{pH}$ between 3 and 6.5 have almost no effect on the response of the $\mathrm{Ca}-\mathrm{ISE}$ (e.g., the potential of the $\mathrm{Ca}-\mathrm{ISE}$ measured with $\left[\mathrm{Ca}^{2+}\right]$ $=10^{-3} \mathrm{M}$ at $\mathrm{pH} 3$ and 6.5 differed by only $3 \mathrm{mV}$ ), (ii) the components of the BSF system do not interfere with the functioning of the $\mathrm{Ca}-\mathrm{ISE}$, and (iii) $\mathrm{Ca}^{2+}$ ions do not disturb the oscillatory behavior of the BSF mixture.

$\mathrm{Ca}^{2+}$ Pulses Induced by the BSF Oscillator. Figure 2 shows the oscillatory changes in $\mathrm{pH}$, redox potential, and potential of the $\mathrm{Ca}-\mathrm{ISE}$ recorded simultaneously in the CSTR when a mixture of the standard BSF oscillator and [CaEDTA] $=2.5 \times$ $10^{-3} \mathrm{M}$, our estimated optimum concentration, are introduced. As seen in Figure 2a,c, the $\mathrm{pH}$ oscillations induce a relatively large ( 2 orders of magnitude) variation in the concentration of free calcium ions, which appear in pulses in this combined system. Figure 3 shows how the electrode responses seen in Figure 2 are modified when the input feed of $\mathrm{NaBrO}_{3}+$ 


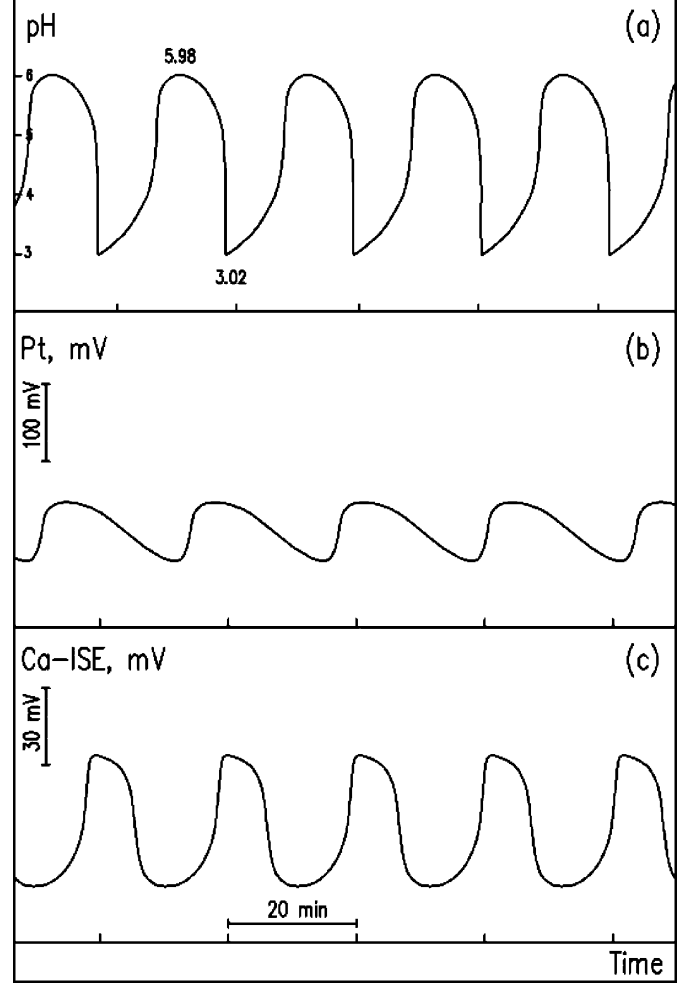

Figure 2. Oscillations in $\mathrm{pH}(\mathrm{a})$, redox potential (b), and potential of a Ca-ISE (c) in the BSF-CaEDTA system. [CaEDTA] $=2.5 \times 10^{-3}$ M. All other parameters as in Figure 1.

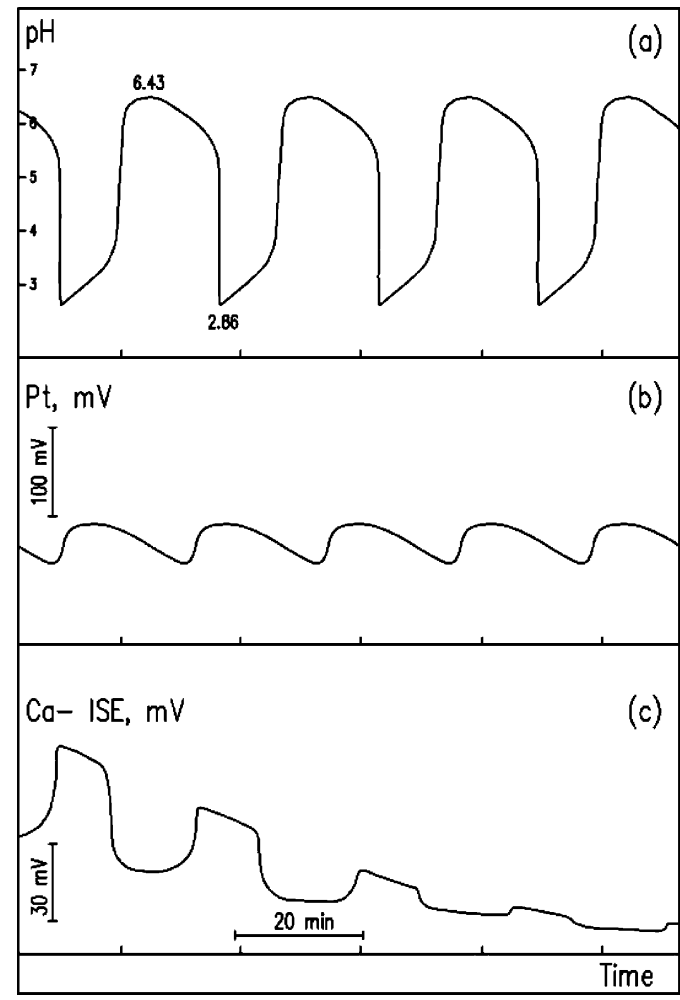

Figure 3. Changes in $\mathrm{pH}(\mathrm{a})$, redox potential (b), and potential of a $\mathrm{Ca}$-ISE (c) when the CaEDTA is washed out of the CSTR. Parameters as in Figure 2.

CaEDTA is replaced with $\mathrm{NaBrO}_{3}$. The $\mathrm{Ca}$-ISE signal dies away completely as CaEDTA is washed out of the CSTR by the flow of $\mathrm{BrO}_{3}{ }^{-}$. The oscillations in $\left[\mathrm{Ca}^{2+}\right]$ are restored and then cease again within 4-5 residence times when the renewal and removal of the CaEDTA input are repeated. The small

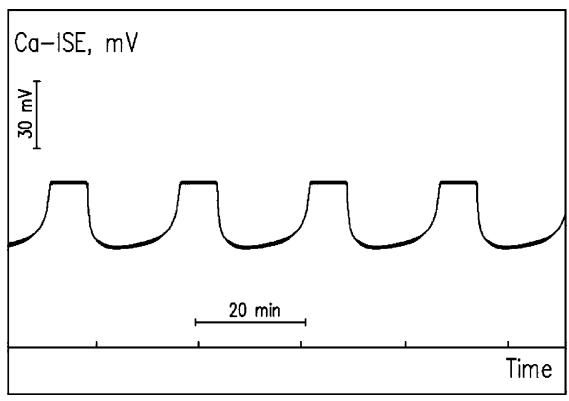

Figure 4. Oscillation in $\left[\mathrm{Ca}^{2+}\right]$ with input $[\mathrm{CaEDTA}]$ half that in Figure 2c. All other parameters as in Figure 2.

increases in the amplitude of the $\mathrm{pH}$ (Figure 3a) and Pt (Figure $3 b)$ oscillations and in the length of the period are due to removal of the buffering species, the ligand EDTA. In separate experiments, the input $\mathrm{NaBrO}_{3}+$ CaEDTA solution is replaced with $\mathrm{NaBrO}_{3}+\mathrm{Na}_{2}$ EDTA. Here the trace of the $\mathrm{Ca}$-ISE damps exactly as in Figure $3 \mathrm{c}$, but the $\mathrm{pH}$ and $\mathrm{Pt}$ electrodes respond as in Figure 2a,b.

To establish the upper and lower limits of [CaEDTA] in the CSTR that permit $\mathrm{Ca}^{2+}$ oscillations, we measured the response of the $\mathrm{Ca}-\mathrm{ISE}$ over a range of input [CaEDTA] with the standard BSF oscillator. With [CaEDTA] $=2.5 \times 10^{-5}, 2.5 \times$ $10^{-4}, 2.5 \times 10^{-3}, 5.0 \times 10^{-3}$, and $1.0 \times 10^{-2} \mathrm{M}$, the Ca-ISE gives oscillatory responses with amplitudes of 18, 36, 50, 51, and $20 \mathrm{mV}$, respectively. These data enable us to establish the optimum [CaEDTA] in the BSF-EDTA system as $2.5 \times 10^{-3}$ to $5 \times 10^{-3} \mathrm{M}$ under our experimental conditions. At low values of [CaEDTA], increasing [CaEDTA] results in a larger amplitude of $\mathrm{Ca}^{2+}$ oscillation, but as [CaEDTA] rises the stronger buffering effect attenuates, and eventually shuts down the $\mathrm{pH}$ oscillations in the core system, thereby suppressing the $\mathrm{Ca}^{2+}$ oscillations as well.

The shape of the oscillatory $\mathrm{Ca}$-ISE signal also changes as [CaEDTA] is varied. Figure 4 shows the oscillations in the $\mathrm{Ca}$-ISE potential when the input [CaEDTA] in Figure 2 is halved. The near-sinusoidal shape seen in Figure $2 \mathrm{c}$ becomes more rectangular as [CaEDTA] is lowered.

The behavior of the system is also sensitive to the flow rate $k_{0}$. We examined the BSF-CaEDTA system at [CaEDTA $]=$ $5 \times 10^{-3} \mathrm{M}$ over a range of flow rates. When the CSTR was filled with the reagents at our maximum flow rate, $k_{0}=5.3 \times$ $10^{-3} \mathrm{~s}^{-1}$, and this flow rate was maintained, a high $\mathrm{pH}(5.94)$ steady state associated with a steady low free $\left[\mathrm{Ca}^{2+}\right]$ was found. When $k_{0}$ was decreased to $2.0 \times 10^{-3} \mathrm{~s}^{-1}$, high amplitude (52 $\mathrm{mV}$ ) oscillations in the signal of the $\mathrm{Ca}-\mathrm{ISE}$ were recorded with a sharp peak at the upper part of the oscillatory traces. Oscillations with $k_{0}=1.45 \times 10^{-3} \mathrm{~s}^{-1}$ (our "standard" flow rate) are shown Figure 2c. When $k_{0}$ was further decreased to $1.0 \times 10^{-3} \mathrm{~s}^{-1}$, the oscillatory state was converted to a low $\mathrm{pH}$ (4.2) steady state with a high free $\left[\mathrm{Ca}^{2+}\right]$.

Bistability is commonly associated with chemical oscillators in a CSTR. ${ }^{1}$ In the core BSF system at $20^{\circ} \mathrm{C}$, a wide range of hysteresis was observed in the $\mathrm{pH}$ as a function of flow rate. ${ }^{5}$ At a composition in the bistable domain of the $\mathrm{pH}$ vs $k_{0}$ phase diagram of the BSF oscillator, we found hysteresis in the presence of $10^{-3} \mathrm{M}$ CaEDTA at $20{ }^{\circ} \mathrm{C}$. The results shown in Figure 5 indicate that the bistability associated with the BFS system is preserved and induces two steady states in $\left[\mathrm{Ca}^{2+}\right]$. At high flow rates the $\mathrm{pH}$ remains high $(\sim 6.4)$ due to the low extent of the reaction in the core oscillator, and consequently the free $\left[\mathrm{Ca}^{2+}\right]$ is low. This state, designated as SS I in the figure, is transformed to a low $\mathrm{pH}$-high $\left[\mathrm{Ca}^{2+}\right]$ steady state (SS II) 




Figure 5. Hysteresis loop in the $\mathrm{pH}$ (a) and in the potential of a $\mathrm{Ca}$-ISE (b) measured in the BSF-CaEDTA flow system. Parameters as in Figure 2, except $[$ CaEDTA $]=1.0 \times 10^{-3} \mathrm{M}$ and $T=20^{\circ} \mathrm{C}$.

when $k_{0}$ is decreased below $4 \times 10^{-3} \mathrm{~s}^{-1}$. On increasing the flow rate, the reverse transition occurs at $k_{0}=9 \times 10^{-3} \mathrm{~s}^{-1}$. Between the two transition points the system can be shifted between SS I and SS II by applying acidic or basic perturbations. The threshold $\mathrm{pH}$ is about 5 . If $\mathrm{pH}>5$ or $\mathrm{pH}<5$ is reached in the CSTR after perturbation, the system evolves to the low $\left[\mathrm{Ca}^{2+}\right]$ or the high $\left[\mathrm{Ca}^{2+}\right]$ steady state, respectively.

Visualizing the $\mathrm{Ca}^{2+}$ Pulses. The BSF-CaEDTA system undergoes oscillations in electrochemical potential (e.g., signals of $\mathrm{Pt}$, glass electrodes, and $\mathrm{Ca}-\mathrm{ISE}$ ) without observable color changes. Since we are interested in observing spatial pattern formation as well as temporal oscillation in calcium oscillators, we sought an indicator that makes the oscillations in $\left[\mathrm{Ca}^{2+}\right]$ visible. Examples of such pattern formation include traveling spiral waves ${ }^{7}$ and stationary Turing structures ${ }^{8}$ in the BelousovZhabotinsky (BZ) and chlorite-iodide-malonic acid (CIMA) chemical systems, respectively, and $\mathrm{Ca}^{2+}$ spiral waves observed in developing frog oocytes. ${ }^{9}$

Periodic changes in color may occur in a chemical oscillator as a result of formation of a colored intermediate (e.g., in many uncatalyzed bromate oscillators ${ }^{10}$ ), generation of a colored complex acting as a catalyst (e.g., ferroin in the BZ oscillator ${ }^{11}$ ), or the use of indicators for an oscillating species (e.g., starch for iodine in the CIMA reaction ${ }^{8}$ ). In the BSF-CaEDTA system, the solution is pale yellow due to the presence of $\mathrm{Fe}(\mathrm{CN})_{6}{ }^{4-}$ and $\mathrm{Fe}(\mathrm{CN})_{6}{ }^{3-}$. Oscillations in the free $\left[\mathrm{Ca}^{2+}\right]$ can be visualized by adding Arsenazo(III) dye to the input solution of $\mathrm{BrO}_{3}{ }^{-}$and CaEDTA. The dye forms a blue 1:1 complex with $\mathrm{Ca}^{2+}\left(\lambda_{\max }\right.$ $=655 \mathrm{~nm}$ ), while the free ligand is pink or cherry red depending on its concentration. ${ }^{12}$ Since the color of the dye may also depend on the $\mathrm{pH}$, we examined the behavior of the indicator in the BSF oscillatory mixture. In the presence of Arsenazo(III) but in the absence of CaEDTA, no changes in the red color occur in the BSF system during the $\mathrm{pH}$ and redox potential oscillations. If CaEDTA is also present, periodic color changes are observed. At low $\mathrm{pH}$ (high free $\left[\mathrm{Ca}^{2+}\right]$ ) the reaction mixture is violet, corresponding to formation of the $\mathrm{Ca}^{2+}-$ Arsenazo(III) complex. At high $\mathrm{pH}$ (low free $\left[\mathrm{Ca}^{2+}\right]$ ), the solution is cherry red, the color of free Arsenazo(III). The bistable BSFCaEDTA-Arsenazo(III) system is red in SSI and violet in SSII.

These color changes observed in the bistable or the oscillatory BSS-CaEDTA reaction are not as dramatic as in some other systems that produce patterns in thin solution layers. We are therefore continuing our efforts to find better dyes (e.g., fluorophores) to visualize the changes in $\left[\mathrm{Ca}^{2+}\right]$ that occur in the BSF-CaEDTA system.

\section{Discussion}

We have produced, recorded, and visualized oscillations in the concentration of free calcium ions by combining two independent subsystems, the BSF pH oscillator and the complex

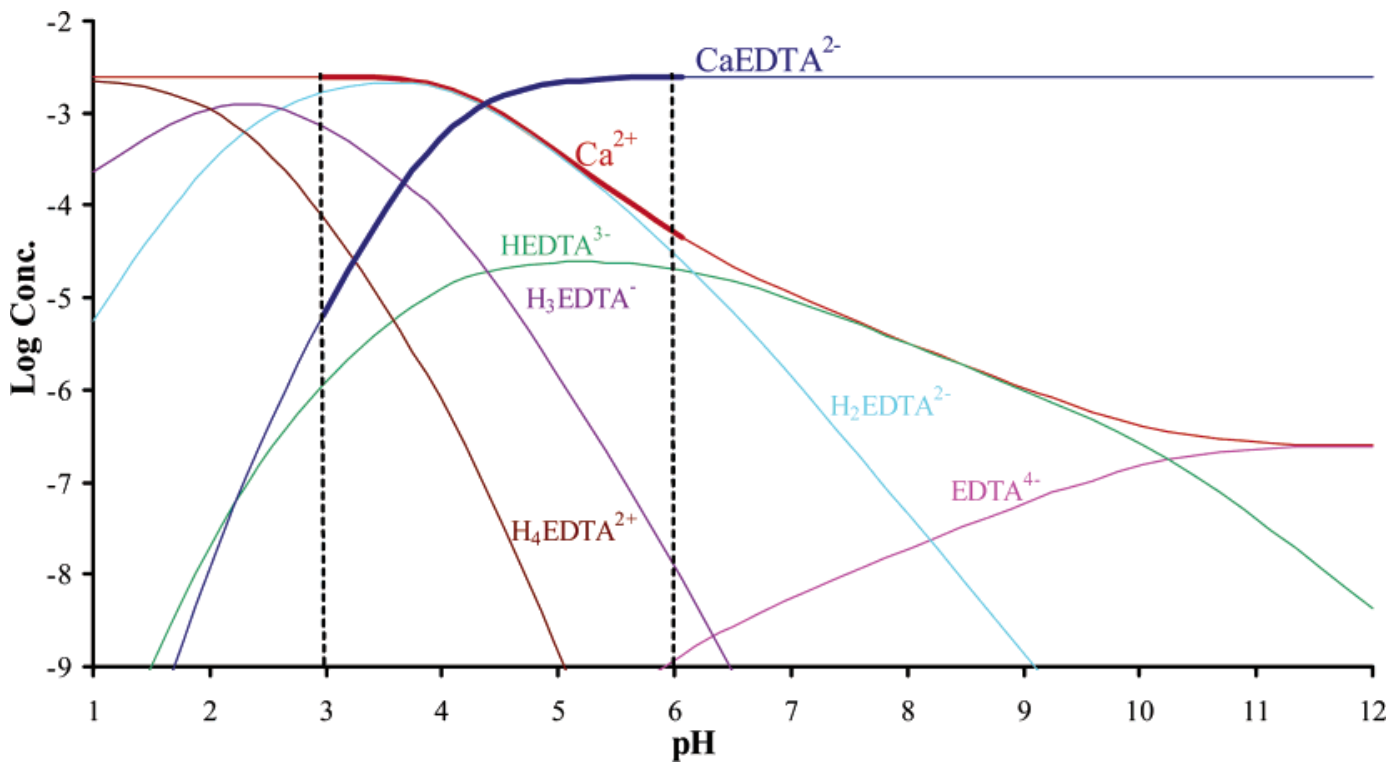

Figure 6. Distribution of species in the $\mathrm{Ca}^{2+}+\mathrm{EDTA}^{4-} \leftrightarrow \mathrm{CaEDTA}^{2-}$ equilibrium as a function of pH calculated at $\left[\mathrm{Ca}^{2+}\right]_{\mathrm{TOT}}=[\mathrm{EDTA}]_{\mathrm{TOT}}=$ $2.50 \mathrm{mM}$. 
formation equilibrium between $\mathrm{Ca}^{2+}$ and EDTA. The dynamical behavior of the combined system is determined by the properties of both subsystems. In this work, our goal was to induce large amplitude oscillations in the response of a Ca-ISE. Therefore, the two subsystems were tuned to generate large oscillatory changes in $\left[\mathrm{Ca}^{2+}\right]$. The mixture of the standard BSF oscillator and $[$ CaEDTA $]=2.5 \times 10^{-3} \mathrm{M}$ was found to represent such an optimal system.

The distribution of all species that participate in the $\mathrm{Ca}^{2+}+$ EDTA $\leftrightarrow$ CaEDTA equilibrium was calculated as a function of $\mathrm{pH}$ using the MEDUSA software package ${ }^{13}$ at initial concentrations $\left[\mathrm{Ca}^{2+}\right]=[$ EDTA $]=2.5 \times 10^{-3} \mathrm{M}$ (with the protonation constants of EDTA and the formation constant of CaEDTA taken from ref 6). The results are shown in Figure 6. At $\mathrm{pH} 3$ and 6 (the $\mathrm{pH}_{\min }$ and $\mathrm{pH}_{\max }$ in the core oscillator at $[$ CaEDTA $\left.]=2.5 \times 10^{-3} \mathrm{M}\right)$, the calculated free $\left[\mathrm{Ca}^{2+}\right]$ is 1.0 $\times 10^{-5} \mathrm{M}$ and $2.4 \times 10^{-3} \mathrm{M}$, respectively. The amplitude of potential oscillation of the $\mathrm{Ca}$-ISE measured in the combined system under the same experimental conditions is $51 \mathrm{mV}$ (Figure 2c), which, using the Nernst equation and our observed 27 $\mathrm{mV} /$ decade response, corresponds to almost a 100-fold change of $\left[\mathrm{Ca}^{2+}\right]$ at $30{ }^{\circ} \mathrm{C}$.

The encouraging agreement between the measured and calculated changes in $\left[\mathrm{Ca}^{2+}\right]$ during the oscillatory cycle demonstrates that reactions that produce pulses of otherwise nonoscillatory species can be designed by the method described in ref 3. Using other oscillators and other acid-base, complexation, or precipitation equilibria, it should be possible to generate periodically varying concentrations of many free metal ions or anions, including species such as $\mathrm{Zn}^{2+}, \mathrm{Al}^{3+}, \mathrm{Ba}^{2+}$, or $\mathrm{F}^{-}$, which are not capable of participating as reagents in redox chemistrybased chemical oscillators. Ultimately, we hope to be able to utilize these new chemical oscillators for applications such as pattern formation, modulating the structure of ion-sensitive hydrogels, and coupling to biological systems, though achieving the last goal will require addressing issues of biocompatibility as well.

Acknowledgment. This work was supported by grants from the Hungarian Academy of Sciences (HAS) (OTKA Nos. T 043743 and K 62029), the U.S. National Science Foundation (NSF CHE-0306262), and a U.S.-Hungarian Cooperative Research Grant from NSF and HAS. We thank Sarah Robinson for assistance with several of the experiments.

\section{References and Notes}

(1) Epstein, I. R.; Pojman, J. A. Introduction to Nonlinear Chemical Dynamics: Oscillations, Waves, Patterns and Chaos; Oxford University Press: New York, 1998. 1217.

(2) Sagués, F.; Epstein, I. R. J. Chem. Soc., Dalton Trans. 2003, 1201-

(3) Kurin-Csörgei, K.; Epstein, I. R.; Orbán, M. Nature 2005, 433, $139-142$.

(4) Berridge, M. J. J. Biol. Chem. 1990, 265, 9583-9586.

(5) Edblom, E. C.; Luo, Y.; Orbán, M.; Kustin, K.; Epstein, I. R. J. Phys. Chem. 1989, 93, 2722-2727.

(6) Skoog, D. A.; West, D. M.; Holler, F. J. Fundamentals of Analytical Chemistry, 6th ed.; Saunders Coll. Publ.: Forth Worth, TX, 1992.

(7) Zaikin, A. N.; Zhabotinsky, A. M. Nature 1970, 225, 535-537.

(8) Castets, V.; Dulos, E.; Boissonade, J.; De Kepper, P. Phys. Rev. Lett. 1990, 64, 2953-2956.

(9) Camacho, P.; Lechleiter, J. D. Science 1993, 260, 226-229.

(10) Körös, E.; Orbán, M. Nature 1978, 273, 371-372.

(11) Field, R. J.; Burger, M. Oscillations and Traveling Waves in Chemical Systems; Wiley: New York, 1985.

(12) Savrin, S. B. Organic Reagents in the Group of Arsenazo(III); Atomizdat: Moscow, 1971.

(13) Puigdomenech, I. Chemical Equilibrium Software, MEDUSA, http://web.telia.com/ u156511596. 